\title{
Potencial contaminante del mar por aguas residuales de las industrias de harinas y aceites de pescado
}

\author{
Por Santiago Mendiola ${ }^{{ }^{*}}$, Juan J. Achútegui ${ }^{1}$, Francisco J. Sánchez ${ }^{1}$ y M. ${ }^{a}$ José San José \\ 'Departamento de Ciencias y Técnicas de la Navegación y Construcción Naval, \\ Universidad de Cantabria, Gamazo, 1. 39004 - Santander. \\ ${ }^{2}$ Departamento de Ingeniería Química, Facultad de Ciencias. \\ Universidad del País Vasco, Apartado 644, 48080 - Bilbao.
}

\begin{abstract}
RESUMEN
Potencial contaminante del mar por las industrias de harinas y aceites de pescado.

En este trabajo se evalúa el potencial contaminante que representa el vertido al mar de los desechos procedentes de las industrias de harinas y aceites de pescado. Para ello se han analizado algunos aspectos de la composición físico-química y bacteriológica de los efluentes residuales de estas industrias, incluyendo entre otros: porcentaje en peso de materia orgánica, demanda química de oxígeno, saturación de ácidos grasos y presencia de Salmonellas. Los resultados muestran en general un bajo potencial contaminante de estas aguas residuales, aunque su $\mathrm{pH}$ ácido y el alto grado de saturación encontrado en los ácidos grasos de los aceites de pescado podrían conllevar una cierta toxicidad para el medio marino.
\end{abstract}

PALABRAS-CLAVE: Aceite de pescado - Contaminación marina - Harina de pescado - Residuo industrial.

\section{SUMMARY}

Polluting potential of wastewater from fish meal and oil industries.

In this study we addressed the polluting potential that constitutes the disposal of wastewater from the fish meal and oil industries into the sea. With this aim we have analysed some phisico-chemical and bacteriologic aspects of the effluents of these industries, including: weight percentage of organic matter, chemical oxygen load, fatty acids saturation, and presence of Salmonellas. The results sugges a low polluting potential for these effluents, although the acid $\mathrm{pH}$ and the high rate of saturation found in fatty acids of oil fishes could imply a certain toxicity for the marine environment.

KEY-WORDS: Fish meal - Fish oil - Industrial waste - Marine pollution.

\section{INTRODUCCIÓN}

La importancia cada día mayor que en la economía mundial adquieren las grasas, hace que la obtención de aceites a partir de los animales marinos haya venido a ser una de las principales industrias derivadas de la pesca. Anualmente se emplean en el mundo varios millones de toneladas métricas de di- ferentes clases de pescado y marisco para la obtención de harina y aceite de pescado (Bimbo, 1992). Proceden de las partes de los peces no empleadas para el consumo humano y se emplean para usos diversos, como la fabricación de margarinas, barnices y pinturas (aceites), y como componentes de los piensos compuestos para la alimentación animal (harinas) (Allen, 1995).

El proceso de fabricación de las harinas y aceites de pescado en las factorías costeras supone el vertido al mar de un cierto volumen de aguas residuales, cuya cantidad precisa y potencial contaminante no es bien conocido. En países de Sudamérica como Perú y Chile, con una producción enorme de aceites y harinas de pescado, se han descrito episodios de toxicidad en el medio marino que se han relacionado con el vertido de dichas aguas residuales (Chang-Reyes, 1970; Cifuentes y col., 1970), aunque no se han realizado estudios que evalúen directamente la relación causa-efecto de dicha toxicidad. En España, las industrias de extracción de harina y aceite de pescado se clasifican en el grupo A de las Industrias Alimentarias, con una actividad de productos tóxicos y peligrosos de clase 3 dentro de la escala de peligrosidad (Plan Ambiental Confesbank, 1991). Sin embargo, esta asignación parece realizada según criterios empíricos, no existiendo estudios experimentales que caracterizen la peligrosidad real de los vertidos de estas industrias.

Como un primer paso en la evaluación del potencial contaminante de los vertidos al mar procedentes de las industrias de harinas y aceites de pescado, en este trabajo se ha analizado la composición físicoquímica y bacteriológica de las aguas residuales de estas industrias, especialmente aquellos aspectos que determinan la calidad de las aguas.

\section{MATERIAL Y MÉTODOS}

\subsection{Muestras}

Las muestras de aguas residuales objeto del presente estudio fueron obtenidas en la factoría de ha- 
rinas y aceites de pescado de Santoña, antes de su vertido al mar y tras el procesamiento de pesca realizada en la costa cantábrica en verano de 1994. El proceso de fabricación de harinas y aceites de pescado (San José y col., 1995) se esquematiza en la Figura 1.

Los análisis fueron realizados sobre 5 muestras de $500 \mathrm{cc}$ tomadas del efluente en 5 días sucesivos (total 2,5 litros). Todas las tomas se realizaron en frascos de cristal herméticos y estériles, rellenando completamente los recipientes, y se mantuvieron a $4^{\circ} \mathrm{C}$ por un período no superior a 6 días hasta su análisis. Las características físico-químicas y bacteriológicas del efluente analizadas fueron: temperatura, $\mathrm{pH}$, tamaño de partículas, porcentaje en peso de materia orgánica, demanda química de oxígeno (DQO), y presencia o ausencia de Salmonellas. Adicionalmente, dada la relativamente alta cantidad de grasas presentes en el efluente analizado se obtuvieron muestras de aceites semirrefinados de diferentes tipos de pescado (anchoa, atún, y sardina) en la factoría de Santoña y se analizaron las proporciones y grado de saturación de los ácidos grasos que contienen estos aceites.

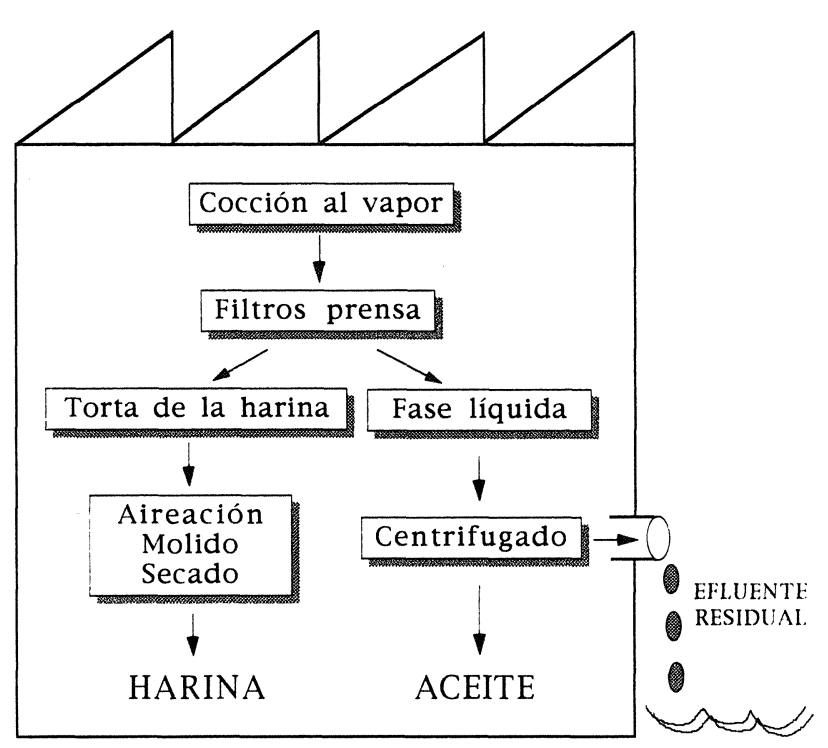

Figura 1

Esquema del proceso de fabricación de aceites y harinas de pescado en la factoría de Santoña. Los restos de pescado se cuecen al vapor en recipientes herméticos de acero inoxidable tras lo que se pasan por unas prensas con filtros obteniéndose una fase sólida (torta de la harina) y una fase líquida. La torta de harina se muele y se seca en hornos rotatorios mediante aire caliente obteniéndose la harina de pescado, sin que de lugar esta operación a efluentes líquidos. La fase líquida se centrifuga y se extrae

el aceite de pescado. El efluente residual, conteniendo agua, sangre, $y$ una pequeña cantidad de grasas en emulsión se envia por un emisario al mar

\subsection{Determinaciones analíticas}

El porcentaje en peso de materia orgánica se obtuvo estableciendo la diferencia entre residuos secos al evaporar el agua a $110^{\circ} \mathrm{C}$, y los residuos calcinados mediante evaporación a $600^{\circ} \mathrm{C}$ (Rodier, 1990). La DQO se midió mediante el digestor ECO (SHARLAU) Ref. 100120, que presenta selector de temperatura en un rango hasta $200^{\circ} \mathrm{C}$ y tiempo de reflujo variable entre 0-120 minutos. El análisis bacteriológico de Salmonellas se realizó mediante siembra e incubación de las muestras en medios de cultivo selectivos, y posterior identificación de las colonias sospechosas con test bioquímicos, según procedimientos previamente descritos (Rodier, 1990). El perfil de ácidos grasos de los aceites de pescado se obtuvo mediante cromatografía gas-líquido con un cromatógrafo Perkin-Elmer 8600, equipado con una columna semicapilar Supercoport 100/120 1741-F, de $2 m$ y $1 / 8$ " (TEKNOKROMA 18032-F). La secuencia de ensayo fue calentamiento en horno a $210^{\circ} \mathrm{C}$, durante $50 \mathrm{~min}$., utilizando $\mathrm{N}_{2}$ como gas portador con una velocidad del gas de $20 \mathrm{ml} / \mathrm{min}$.

\section{RESULTADOS}

En la Tabla I se muestran los valores de los distintos parámetros de calidad analizados en el efluente residual objeto del presente estudio. Los valores mostrados representan el promedio de 5 determinaciones analíticas realizadas en las 5 muestras. Las diferencias no fueron estadísticamente significativas $(p<0,01)$. Hay que destacar la elevada proporción de materia orgánica que corresponde al $4,5 \%$ del peso del efluente y se compone principalmente de grasas, así como el pH de 5,5 moderadamente ácido.

Tabla I

Parámetros físico-químicos y bacteriológicos analizados en el efluente residual de la factoría de harinas y aceites de pescado de Santoña

\begin{tabular}{lc}
\multicolumn{2}{c}{ Parámetros de calidad del efluente } \\
\hline Materia orgánica (\% total) & $4,5 \%$ \\
Grasas & $3,1 \%$ \\
Proteínas & $1,2 \%$ \\
Otros & $0,2 \%$ \\
DQO total (mg/l) & 300 \\
Temperatura & $20^{\circ} \mathrm{C}$ \\
pH & 5,5 \\
Tamaño de las partículas & $<2 \mu \mathrm{m}$ \\
Salmonellas & Negativo \\
\hline
\end{tabular}


En la Tabla II, se muestran las proporciones de ácidos grasos totales $\mathrm{C}_{14}, \mathrm{C}_{16}, \mathrm{C}_{18}, \mathrm{C}_{20}$ y $\mathrm{C}_{22}$, así como el grado de saturación de los ácidos grasos presentes en las muestras analizadas de aceites de anchoa, atún, y sardina. Es de destacar la elevada proporción de ácidos grasos poliinsaturados que presentan los aceites de pescado. El perfil cromatográfico de ácidos grasos correspondiente al aceite de atún se muestra en la figura 2.

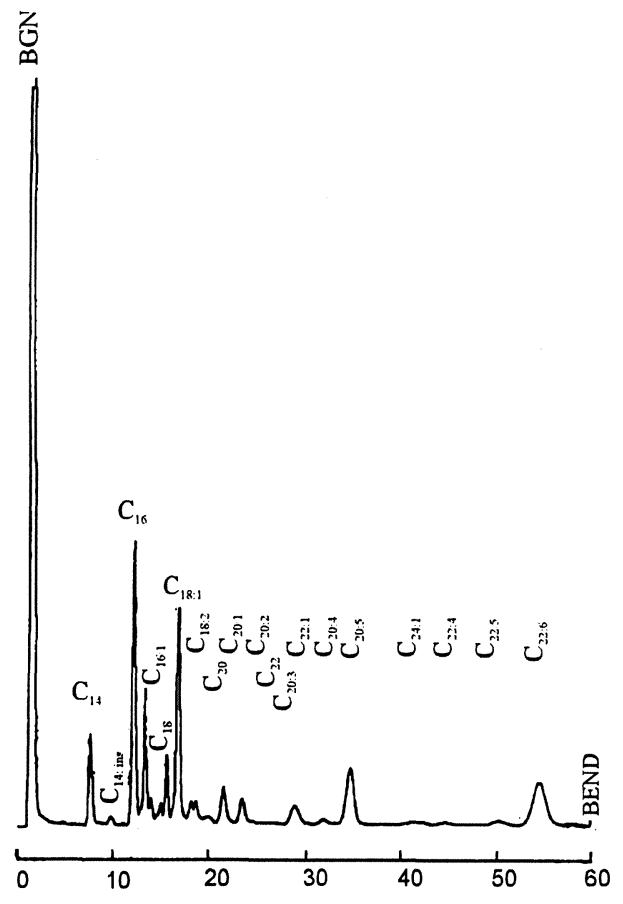

Figura 2

Perfil cromatográfico de ácidos grasos contenidos en el aceite semirrefinado de atún

Tabla II

Composición en ácidos grasos y grado de saturación (en porcentajes en peso) de los aceites de pescado semirrefinado de anchoa, atún y sardina

\begin{tabular}{lrrr}
\hline & Anchoa & \multicolumn{1}{c}{ Atún } & Sardina \\
\hline $\mathrm{C}_{14}$ total & 7.24 & 7.78 & 9.65 \\
$\mathrm{C}_{16}$ total & 27.45 & 24.98 & 24.06 \\
$\mathrm{C}_{18}$ total & 16.80 & 20.15 & 19.92 \\
$\mathrm{C}_{20}$ total & 30.50 & 30.26 & 18.67 \\
$\mathrm{C}_{22}$ total & 13.96 & 10.68 & 23.95 \\
Otros & 4.05 & 6.15 & 3.75 \\
& & & \\
Saturados & 33.32 & 31.19 & 27.97 \\
Monoinsaturados & 27.90 & 40.92 & 50.25 \\
Pentainsaturados & 16.51 & 8.64 & 7.19 \\
Hexainsaturados & 12.35 & 10.19 & 8.71 \\
\hline
\end{tabular}

\section{DISCUSIÓN}

El efecto contaminante de las Industrias de aceites y harinas de pescado depende fundamentalmente del vertido al mar de los efluentes residuales derivados de los mismos procesos de fabricación. En la factoría de harinas y aceites de pescado de Santoña las aguas residuales suponen aproximadamente un $2 \%$ del peso inicial del pescado utilizado (aprox. 600-900 Tm/año). A esto hay que sumar una cierta cantidad difícilmente cuantificable derivada de lavado de los pozos y tanques utilizados en el proceso de fabricación, así como del lavado de los tanques de los buques que lo transportan para su exportación (Achútegui et al., 1993, Mendiola y col., 1995).

El porcentaje en peso de materia orgánica del efluente residual analizado en este trabajo fue del $4,5 \%$. El inconveniente de las materias orgánicas es que favorecen la aparición de malos gustos y facilitan el desarrollo de gérmenes, algas y hongos. $\mathrm{El}$ análisis bacteriológico es de especial interés ante la posibilidad de que los vertidos residuales en el mar estén en proximidad con baños, playas, o criaderos y parques conchíferos. Aunque el porcentaje obtenido parece algo elevado, para la interpretación de los resultados hay que correlacionarlos con otros parámetros relacionados: DQO y análisis bacteriológico. La DQO, que corresponde al conjunto de materias orgánicas que tienen un carácter biodegradable o no, fue de $300 \mathrm{mg} / \mathrm{l}$, valores que se encuentran dentro de lo admisible en la reglamentación de vertidos industriales (IHOBE, 1994). Por otro lado, la ausencia de Salmonellas en el agua analizada hace poco probable la presencia patológicamente significativa de los patógenos facultativos, coliformes o no, dada la correlación existente entre ambos (García-Garrido, 1986).

El pH del efluente analizado fue moderadamente ácido $(5,5)$. Dicho valor se encuentra cerca del límite inferior con respecto a lo admisible para el vertido de aguas residuales (IHOBE, 1994). El valor de $\mathrm{pH}$ compatible con la vida de los peces está comprendido entre 5 y 9 , pero para la mayoría de las especies acuáticas la zona de $\mathrm{pH}$ favorable se sitúa entre 6 y 7,2. Entre otros factores existe evidencia de que el medio ácido aumenta la toxicidad de los ácidos grasos oleico y linoleico sobre los peces (Spruell, 1984). El efecto tóxico de la disminución del $\mathrm{pH}$ de los vertidos analizados dependerá obviamente de la dilución del vertido en dependencia de las cantidades totales de agua residual y el grado de recambio del medio marino.

Otro factor a tener en cuenta es la relativamente alta concentración de grasas en emulsión encontradas en el efluente residual analizado. Es conocido que en medio húmedo se aceleran los procesos de degradación de las grasas, incluyendo: saponificación, reacciones enzimáticas debidas a bacterias y hongos, así como oxidación, de los que se derivan 
productos de descomposición malolientes, cetonas, aldehídos, y ácidos grasos inferiores. En este contexto, la especial peligrosidad de las grasas del efluente analizado se relaciona con la elevada proporción de ácidos grasos poliinsaturados que presentan los aceites de pescado, que es significativamente mayor que en otros tipos de aceites. En los aceites de pescado analizados los ácidos grasos (Tabla II) contienen hasta seis enlaces dobles, mientras que este número no es mayor de cuatro en los aceites provenientes de animales terrestres y de tres en los aceites vegetales. En nuestro análisis hemos visto como el porcentaje de ácidos grasos pentainsaturados y hexainsaturados es particularmente alto en el aceite de anchoa (cercano al 29\%), siendo algo menor en los aceites de atún (19\%) y sardina (16\%). El gran número de dobles enlaces presentes en los ácidos grasos poliinsaturados implica una alta reactividad con otros compuestos presentes en el medio diluyente, lo que condiciona su peligrosidad. Es conocido que los ácidos grasos libres son un problema frecuente para las estaciones de depuración de aguas residuales puesto que a determinadas concentraciones pueden llegar a provocar un ataque del hormigón y otros elementos estructurales (Rodier, 1990). Por otra parte, se ha comprobado que los derrames de aceites en las aguas producen de manera general efectos subletales en peces así como en algas y zooplancton (Nriagu, 1983), siendo tóxicos de forma aguda para algunas especies (Franco, 1984). También se ha descrito su efecto de afectar al sabor del pescado de consumo (Person, 1984).

El efecto contaminante real de los efluentes analizados en este trabajo dependerá no solamente de su composición sino de otros factores como ritmo de vertido y tasa de recambio del agua en el lugar de vertido. Es muy probable que en la factoría de Santoña, donde las cantidades vertidas son bajas, la contaminación sea mínima o inapreciable, aunque esto sólo puede ser determinado por el estudio de indicadores de degradación biológica del medio marino en los lugares donde se vierten estos efluentes. Por otro lado no es improbable que en otras industrias con mayor producción se pueda producir contaminación apreciable. Por ello, en cualquier caso sería deseable un plan preventivo de descontaminación mediante la disminución del volumen de residuos y el control de los lugares de vertido.

\section{BIBLIOGRAFÍA}

Achútegui, J. J., Mendiola, S. y Díaz, A. (1993). -«Protection from oil pollution caused by the grounding of the tanker -Aegean Sea- in Corunna Spain".- Proceeding VI Congress, IMAM'93, Varna, Bulgaria. Vol. 1, 211-216.

Allen, D. A. (1995). -«Fish oil compositions» en «Fish oil technology nutrition and marketing".- Cap. 6, 95-107. R. J. Hamilton and R. D. Rice (eds.)

Bimbo, A. P., and Crowther, J. B., (1992). - «Fish meal and oil: Current uses».- J. Am.Oil Chemists'Soc. 69, 221-227.

Chang Reyes, L. (1970). - «Contaminantes potenciales que pueden afectar a los organismos del ambiente marino a lo largo de la costa de Perú» en "Marine Pollution and Sea Life».- p. 106. Fishing news Ltd, FAO. Londres.

Cifuentes, J. L., Rodríguez R., Zarur, A. (1970). -«Panorama General de la Contaminación de las Aguas en Méjico» en «Marine Pollution an sea Life».-pp. 100-111. Fishing news Ltd, FAO. Londres.

Franco, P. J. (1984). - «Acute Toxicity of a synthetic oil, aniline and phenol to laboratory and natural populations of chironomide (diptera) larvae».-Environ. Pollut. A34: 321 (Abstract).

García-Garrido, J. (1986). -«Microbiología patógena» en «El agua en la producción. La calidad del agua».- Volumen I, pp. 184-192.

IHOBE, (1994). - «Plan de Gestión de residuos especiales de la Comunidad Autonómica Vasca (C.A.V)».- Ed. IHOBE, 47-49.

Laila, A., Abd allah, M. A., Dabash, A. S., El-Ziny, B. A., and El-Kalioubi, M.H. (1985). -«Fatty acid composition of the fish tissues and wastes os some Egyptian Nile Fish".- Grasas y Aceites 36, 331-334.

Mendiola, S., Achútegui, J. J., Trueba, A., Sánchez, F. J., y Díaz, A. (1995). -«Marine Pollution caused by accidents of oil tankers".- Proceeding of the VIlth Congress, IMAM'95, Dubronik, Croatia: 434-439.

Nriagu, J. O. (1983). -«Aquatic Toxicology.»- John Wiley \& Sons, New York, N. Y.

Person, P. E. (1984). - «Uptake and Release of Environmentally Ocurring Odorous Compounds by Fish".- Water Res. (G.B.) 18: 1263 (Abstract).

Plan Ambiental Confebask, (1991). -«Aportación Empresarial a la mejora del Medio Ambiente en Euskadi».Ed. Ellacuría.

Rodier, J. (1990). -«Análisis de las aguas. Aguas naturales, aguas residuales, agua de mar».- Ediciones OMEGA. Barcelona.

San José, M. J., Achútegui, J. J., Sánchez, F. J., y Mendiola, S. (1995). - «Combustión espontánea de las harinas de pescado azul: Factores de influencia y peligrosidad en el transporte".- Grasas y Aceites 46, 39-44.

Spruell, J. A. (1984). -«Response of Algae ans Zooplankton to C18 Fatty Acids of Chlamydomonas reinhardtii».Hydrobiología (Nth.), 114: 9 (Abstract). 